\title{
The predictive value of PRDM2 in solid tumor: a systematic review and meta-analysis
}

\author{
Caroline Tanadi $^{1}$, Alfredo Bambang ${ }^{2}$, Indra P Wendi ${ }^{2}$, Veronika M Sidharta ${ }^{3}$, Linawati Hananta ${ }^{4}$, Anton Sumarpo \\ Corresp. 2 \\ 1 Undergraduate Medical Program, School of Medicine and Health Sciences, Atma Jaya Catholic University of Indonesia, Jakarta, Indonesia \\ Department of Chemistry and Biochemistry, School of Medicine and Health Sciences, Atma Jaya Catholic University of Indonesia, Jakarta, Indonesia \\ 3 Department of Histology, School of Medicine and Health Sciences, Atma Jaya Catholic University of Indonesia, Jakarta, Indonesia \\ 4 Department of Pharmacy and Pharmacology, School of Medicine and Health Sciences, Atma Jaya Catholic University of Indonesia, Jakarta, Indonesia \\ Corresponding Author: Anton Sumarpo \\ Email address: anton.sumarpo@atmajaya.ac.id
}

Abstract Background. Many studies have reported the presence of Positive Regulatory/Su(var)3-9,Enhancer-of-zeste and Trithorax Domain 2 (PRDM2) downregulation in cancer. However, its potential as a diagnostic biomarker is still unclear. Hence, a systematic review and metaanalysis were conducted to address this issue.

Introduction. As of 2018, cancer has become the second leading cause of death worldwide. Thus, cancer control is exceptionally vital in reducing mortality. One such example is through early diagnosis of cancer using tumor biomarkers. Having a function as a tumor suppressor gene (TSG), PRDM2 has been linked with carcinogenesis in several solid tumor. This study aims to assess the relationship between PRDM2 downregulation and solid tumor, its relationship with clinicopathological data, and its potential as a diagnostic biomarker. This study also aims to evaluate the quality of the studies, data reliability and confidence in cumulative evidence.

Materials \& Methods. A protocol of this study is registered at the International Prospective Register of Systematic Reviews (PROSPERO) with the following registration number: CRD42019132156. PRISMA was used as a guideline to conduct this review. A comprehensive electronic search was performed from inception to June 2019 in Pubmed, Cochrane Library, ProQuest, EBSCO and ScienceDirect. Studies were screened and included studies were identified based on the criteria made. Finally, data synthesis and quality assessment were conducted.

Results. There is a significant relationship between PRDM2 downregulation with solid tumor (RR 4.29, $95 \% \mathrm{Cl} 2.58-7.13, \mathrm{P}<0.00001)$. The overall sensitivity and specificity of PRDM2 downregulation in solid tumors is $84 \%$ (95\% Cl 39-98\%) and $86 \%$ (95\% Cl 71-94\%), respectively. There is a low risk of bias for the studies used. TSA results suggested the presence of marked imprecision. The overall quality of evidence for this study is very low.

Discussion. We present the first meta-analysis that investigated the potential of PRDM2 downregulation as a diagnostic biomarker in solid tumor. In line with previous studies, our results demonstrated that PRDM2 downregulation occurs in solid tumor. A major source of limitation in this study is the small number of studies.

Conclusions. Our review suggested that PRDM2 is downregulated in solid tumor. The relationship between PRDM2 downregulation and clinicopathological data is still inconclusive. Although the sensitivity Peer) reviewing PDF | (2019:12:44160:1:1:NEW 25 Feb 2020) 
and specificity of $P R D M 2$ downregulation are imprecise, its high values, in addition to the evidence that suggested PRDM2 downregulation in solid tumor, hinted that it might still have a potential to be used as a diagnostic biomarker. In order to further strengthen these findings, more research regarding PRDM2 in solid tumors are encouraged. 


\section{The predictive value of PRDM2 in solid tumor: a 2 systematic review and meta-analysis}

3

4

6

7

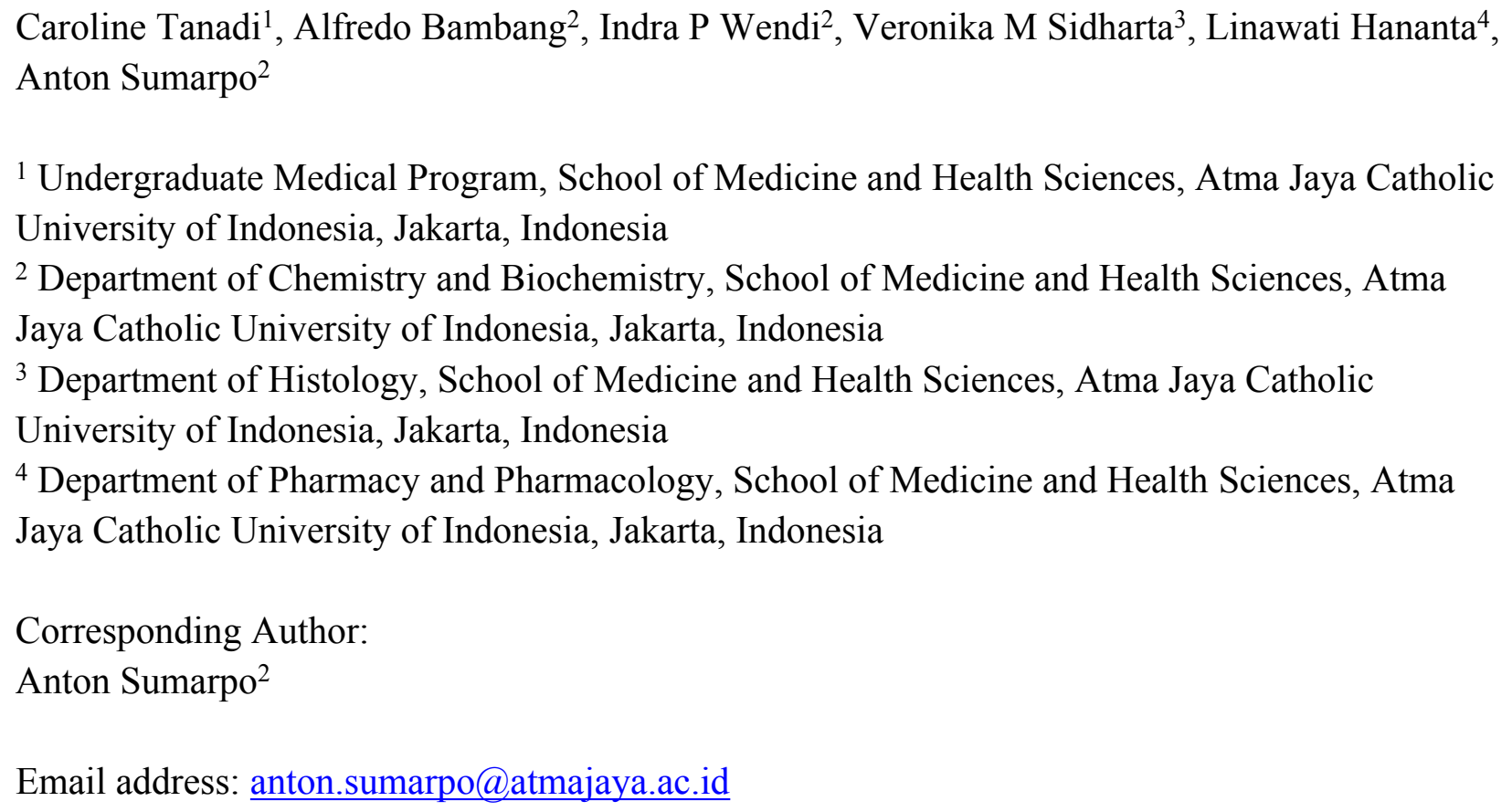

Email address: anton.sumarpo@atmajaya.ac.id

\section{Abstract}

Background. Many studies have reported the presence of Positive Regulatory/Su(var)39, Enhancer-of-zeste and Trithorax Domain 2 (PRDM2) downregulation in cancer. However, its potential as a diagnostic biomarker is still unclear. Hence, a systematic review and meta-analysis were conducted to address this issue.

Introduction. As of 2018, cancer has become the second leading cause of death worldwide. Thus, cancer control is exceptionally vital in reducing mortality. One such example is through early diagnosis of cancer using tumor biomarkers. Having a function as a tumor suppressor gene (TSG), PRDM2 has been linked with carcinogenesis in several solid tumor. This study aims to assess the relationship between PRDM2 downregulation and solid tumor, its relationship with clinicopathological data, and its potential as a diagnostic biomarker. This study also aims to evaluate the quality of the studies, data reliability and confidence in cumulative evidence. Materials \& Methods. A protocol of this study is registered at the International Prospective Register of Systematic Reviews (PROSPERO) with the following registration number: CRD42019132156. PRISMA was used as a guideline to conduct this review. A comprehensive electronic search was performed from inception to June 2019 in Pubmed, Cochrane Library, ProQuest, EBSCO and ScienceDirect. Studies were screened and included studies were identified based on the criteria made. Finally, data synthesis and quality assessment were conducted.

Results. There is a significant relationship between $P R D M 2$ downregulation with solid tumor (RR $4.29,95 \%$ CI $2.58-7.13, \mathrm{P}<0.00001$ ). The overall sensitivity and specificity of PRDM2 
42 downregulation in solid tumors is $84 \%$ (95\% CI 39-98\%) and 86\% (95\% CI 71-94\%),

43 respectively. There is a low risk of bias for the studies used. TSA results suggested the presence

44 of marked imprecision. The overall quality of evidence for this study is very low.

45 Discussion. We present the first meta-analysis that investigated the potential of PRDM2

46 downregulation as a diagnostic biomarker in solid tumor. In line with previous studies, our

47 results demonstrated that PRDM2 downregulation occurs in solid tumor. A major source of

48 limitation in this study is the small number of studies.

49 Conclusions. Our review suggested that $P R D M 2$ is downregulated in solid tumor. The

50 relationship between $P R D M 2$ downregulation and clinicopathological data is still inconclusive.

51 Although the sensitivity and specificity of $P R D M 2$ downregulation are imprecise, its high values,

52 in addition to the evidence that suggested PRDM2 downregulation in solid tumor, hinted that it

53 might still have a potential to be used as a diagnostic biomarker. In order to further strengthen

54 these findings, more research regarding PRDM2 in solid tumors are encouraged.

55

\section{Introduction}

57 Cancer has long been considered a catastrophic public health problem due to its high mortality

58

59

60

61

62

63

64

65

66

67

$68^{-}$

69

70

71

72

73

74

75

76

77

78

79

80

81

82

rates. With an estimate of 9.6 million death, cancer has now become the second leading cause of death worldwide. Moreover, the incidence of cancer is also growing at an alarming rate due to the exponential increase of the aging population and changes in the distribution of cancer risk factors. It was estimated that the incidence of cancer would rise to 18.1 million new cases in 2018. To summarise, 1 in 6 women and 1 in 5 men will develop cancer, while 1 in 10 women and 1 in 8 men are dying as a result of cancer (Bray et al. 2018; World Health Organization 2018).

Thus, cancer control is extremely vital in reducing mortality. One example of cancer control is early diagnosis of cancer. This could be achieved through the use of tumor biomarkers.

However, despite the potential of biomarkers for early detection of cancer, its implementation in the clinical setting is still lacking (Goossens et al. 2015; Schiffman et al. 2015; World Health Organization 2017). This could be attributed to weak clinical performances, such as low sensitivity, low specificity or low predictive values (Diamandis 2012). Hence, further research to identify novel biomarkers should be performed.

Positive Regulatory/Su(var)3-9, Enhancer-of-zeste and Trithorax Domain 2 (PRDM2) is a tumor suppressor gene (TSG) that regulates protein expression through the methylation of lysine 9 in histone H3. Hence, PRDM2 also belongs to the nuclear histone/protein methyltransferase superfamily. Its gene products are also involved in DNA-binding and transcription factor binding-activities, implicating its role in carcinogenesis (Sorrentino et al. 2018; Zhang et al. 2015). Studies have also reported PRDM2 downregulation in cancers that exhibit high incidence and mortality, such as bladder cancer, breast cancer, cervical cancer, colorectal cancer, endometrial cancer, esophageal squamous cell carcinoma, gastric carcinoma, hepatocellular carcinoma, lung cancer, pancreatic cancer, prostate cancer, T-cell prolymphocytic leukemia and

Peer) reviewing PDF | (2019:12:44160:1:1:NEW 25 Feb 2020) 
83 thyroid carcinoma (Cheng et al. 2010; Cui et al. 2016; Johansson et al. 2018; Lal et al. 2006;

84 Michalak \& Visvader 2016; Oshimo et al. 2004; Pandzic et al. 2017; Rossi et al. 2009; Sakurada

85 et al. 2001; Tan et al. 2014; Wu et al. 2016; Yang et al. 2017; Zhang et al. 2016). Furthermore, in

86 a meta-analysis that found a total of 22 genes methylated in hepatocellular carcinoma, PRDM2

87 was one of the genes with the most significant result and is on par with the well-known $A P C$ and

88 p16 (Zhang et al. 2016). Hence, PRDM2 might play an important role in malignancies. However,

89 the potential of $P R D M 2$ as a diagnostic biomarker is still unclear.

90

91

92

Therefore, we performed a systematic review and meta-analysis that investigated PRDM2

expression level in solid tumor, as well as its potential as a diagnostic biomarker. If there is

93

sufficient data, we will also investigate if there is any correlation between PRDM2 expression

94 level with clinicopathological data.

95

96

\section{Materials and Methods}

\section{Study Registration and Methodology}

98

99

100

101

102

103

104

105

106

107

108

109

110

111

112

113

114

115

116

117

118

119

120

121

122

A protocol of this study is registered at the International Prospective Register of Systematic Reviews (PROSPERO) with the following registration number: CRD42019132156

(https://www.crd.york.ac.uk/prospero/display record.php?RecordID=132156) (National Institute for Health Research). Preferred Reporting Items for Systematic Reviews and Meta-analyses (PRISMA) flow diagram was used as a guideline to conduct our systematic review and metaanalysis (Moher et al. 2009).

\section{Search Strategy and Study Selection}

A comprehensive electronic search was done in PubMed, Cochrane Library, ProQuest, EBSCO and ScienceDirect from inception to July 2019 using the following search terms: (PRDM2 OR RIZ OR RIZ1 OR RIZ2 OR KMT8 OR KMT8A OR MTB-ZF OR HUMHOXY1) AND (Cancer OR Cancers OR Malignant OR Malignancy OR Malignancies OR Neoplasm OR Neoplasms OR Neoplasia OR Neoplasias OR Tumor OR Tumors OR Tumour OR Tumours). The search was performed by two independent reviewers (Alfredo Bambang and Indra Putra Wendi). Any differences were solved through a discussion with a third reviewer (Anton Sumarpo).

All of the search outputs were exported into the EndNote software. Duplicates were removed, and screening was performed based on the title and abstract of the study. Probable or included studies were identified and assessed for eligibility according to the criteria above. Finally, included studies were identified, and data extraction was performed.

A study is included if it meets the following criteria: (1) The study used human subjects; (2) The study investigated the relationship between PRDM2 expression level and solid tumor through the use of gene expression analysis; (3) The study used histopathological examination as a comparator; (4) The study is a clinical trial or cross-sectional study. A study is excluded if: (1)

Peer) reviewing PDF | (2019:12:44160:1:1:NEW 25 Feb 2020) 
123 The study does not have a control group (people without cancer or non-cancer specimens); (2)

124 The study did not use an appropriate or did not state the gene expression analysis method used;

125 (3) The expression level of PRDM2 in the study is not clearly stated or unquantifiable; (4) The

126 study is a review, case series, conference abstracts, in vitro or in vivo study. (5) The study is not

127 written in English.

128

129

\section{Data Extraction}

130 The included studies were then analyzed further and the following informations are extracted:

131 First author, publication year, country of origin, age, gender, race, type of cancer, cancer

132 differentiation state, stage of cancer, type of control, number of cases and controls, gene

133 expression analysis method, PRDM2 expression level and conclusion of the study. In the case of

134 missing data, the authors will be contacted via email to request access to those missing data.

135

136

\section{Data Synthesis and Statistical Analysis}

137 Sensitivity and specificity of PDRM2 were assessed in order to elucidate the potential of PRDM2

138 expression level as a diagnostic biomarker in solid tumor. Sensitivity and specificity are said to

139 be significant if $>50 \%$. Risk ratio (RR) with a $95 \%$ confidence interval (CI) was used to

140 determine the relationship between PRDM2 expression level and risk of cancer, as well as the

141 relationship between $P R D M 2$ expression level and clinicopathological data. If heterogeneity is

142 present, Random Effects Model (REM) will be used. However, if heterogeneity is absent, Fixed

143 Effects Model (FEM) will be used instead.

144

145 Cochrane's Q test (chi-squared test) and Higgins $\mathrm{I}^{2}$ statistics were used to assess for the presence

146 of heterogeneity statistically. Heterogeneity is said to be present if $\mathrm{P}<0.10$ or $\mathrm{I}^{2}>75 \%$ (Higgins \&

147 Green 2011; Higgins et al. 2003). To assess for the presence of heterogeneity visually, a forest

148 plot will be generated. Meta-regression and subgroup analysis will be conducted when there are

149 at least 10 studies used in the meta-analysis (Baker et al. 2009). The possible causes of

150 heterogeneity are: Age, gender, ethnicity, country of origin, type of cancer, cancer differentiation

151 state, stage of cancer and genotyping method.

152

153 Funnel plot and Deek's test will be used to assess publication bias when the number of included

154 studies is at least 10. If the funnel plot is asymmetric, publication bias is present. If the P-value

155 for Deek's test is $<0.10$, there is funnel plot asymmetry (Deeks et al. 2005). If publication bias is

156 found, the trim and fill method will be used to correct this bias (Duval \& Tweedie 2000).

157

158 Furthermore, sensitivity analysis was performed to elucidate the effect and stability of a single

159 study on the pooled estimates by deleting one study at a time. Additionally, sensitivity analysis

160 was also conducted to compare the pooled estimates using odds ratio (OR) and RR, as well as

161 using REM and FEM. All statistical analyses were generated using RevMan 5.3 and STATA

16212.0. 
In order to claim that the meta-analysis conducted has been conclusive, the required information

166

167

168

169

170

171

172

173

174

175

176

177

178

179

180

181

182

183

184

185

186

187

188

189

190

191

192

193

194

195

196

197

198

199

200

201

202

size has to be achieved. Thus, a trial sequential analysis (TSA) was performed using TSA software in order to determine the required information size (Wetterslev et al. 2017). Quality of evidence will be assessed using Quality Assessment of Diagnostic Accuracy Studies - 2 (QUADAS-2) which consists of the following key domains: patient selection, index test, reference standard, as well as flow and timing (Whiting et al. 2011).

\section{Confidence in Cumulative Evidence}

Grading of Recommendations, Assessment, Development, and Evaluations (GRADE) was used to evaluate the confidence in cumulative evidence. Overall certainty of evidence can be written as high, moderate, low or very low (Schünemann et al. 2013).

\section{Results}

\section{Search Results}

Using variants of the keywords "PRDM2" and "cancer", we performed a search from inception to July 2019 in PubMed, Cochrane Library, ProQuest, EBSCO and ScienceDirect. After duplicate removal, a total of 3928 records was obtained. Titles and abstracts were screened and 58 potential studies were identified. Out of these 58 studies, 52 were excluded due to the studies being unable to meet the inclusion criteria (ineligible), in vitro and/or in vivo, used unsuitable methods, written in non-English, or is a review. The remaining six studies (Akahira et al. 2007; Dong et al. 2012; Ge et al. 2015; Geli et al. 2005; Jiang et al. 1999; Tan et al. 2018) were included in the systematic review while only five studies (Akahira et al. 2007; Dong et al. 2012; Geli et al. 2005; Jiang et al. 1999; Tan et al. 2018) were included in the meta-analysis. This is because Ge et al. (2015) did not mention the number of samples and controls that expressed PRDM2 downregulation in renal cell carcinoma. Thus, only five studies were included in the meta-analysis. The Preferred Reporting Items for Systematic Reviews and Meta-analyses (PRISMA) flow diagram for this study is shown in Fig. 1.

The studies that were eligible for systematic review were published from 1999 to 2015 . There were a total of 314 samples of solid tumors and 225 controls obtained from patients in China (Dong et al. 2012; Ge et al. 2015; Tan et al. 2018), Japan (Akahira et al. 2007), Sweden (Geli et al. 2005) and United States of America (Jiang et al. 1999). All of these six studies are crosssectional studies. The solid tumors included in this study are ovarian cancer (Akahira et al. 2007), esophageal squamous cell carcinoma (Dong et al. 2012), renal cell carcinoma (RCC) (Ge et al. 2015), pheochromocytoma (Geli et al. 2005), abdominal paraganglioma (Geli et al. 2005), hepatoma (Jiang et al. 1999), lung squamous cell carcinoma (LSCC) (Tan et al. 2018) and lung adenocarcinoma (LAC) (Tan et al. 2018). Out of these six studies, one used immunohistochemistry (IHC) only (Akahira et al. 2007), three used reverse transcription- 
203 polymerase chain reaction (RT-PCR) only (Ge et al. 2015; Geli et al. 2005; Jiang et al. 1999) and 204 two used both IHC and RT-PCR (Dong et al. 2012; Tan et al. 2018). A summary of the main 205 characteristics of the included studies for systematic review and meta-analysis is presented in 206 Table 1 and Table 2, respectively.

207

208

209

\section{Systematic Review Results}

210

All six studies concluded that PRDM2 gene expression is significantly decreased in solid tumor

211 compared to control, with the P-value ranging from $<0.05$ to $<0.001$ using CI 95\%. Akahira et al.

212 (2007) stated that there was a significant correlation between PRDM2 downregulation with

213 cancer grade $(\mathrm{P}<0.0345)$ and stage $(\mathrm{P}<0.0153)$ in ovarian cancer. On the other hand, Ge et al.

214 (2015) stated otherwise, concluding that there was no significant relationship between RCC with tumor progression $(\mathrm{P}=0.19)$. A study by Geli et al. (2005) reported that decreased PRDM2 gene expression was not correlated significantly with gender and tumor size, but was found to be weakly correlated with younger age (Spearman rank-order correlations; $\mathrm{R}=0.4$ ). Other

217 clinicopathological data were either absent or not investigated in the studies. Hence, the role of

218 PRDM2 downregulation in cancer grade, stage, gender, age and other clinicopathological data is

219 still unclear. Due to the lack of sufficient clinicopathological data, only PRDM2 gene expression and its sensitivity and specificity were further analysed in the meta-analysis.

221

222

\section{Meta-Analysis Results}

223 Five studies were included in this meta-analysis to further investigate the relationship between

224

225

226

227

228

229

230

231

232

233

234

235

236

237

238

239

240

241

PRDM2 downregulation with solid tumor (Akahira et al. 2007; Dong et al. 2012; Geli et al. 2005; Jiang et al. 1999; Tan et al. 2018). The pooled analysis suggested that PRDM2 gene expression is decreased in solid tumor (RR 4.29, 95\% CI $2.58-7.13$, P < 0.00001; Fig. 2). Based on this pooled analysis, three sensitivity analyses were conducted to evaluate the stability of our findings: with and without the deletion of Jiang et al. (1999) (Fig. 3), RR or OR (Fig. 4), and FEM or REM (Fig. 5). All three sensitivity analyses did not have meaningful differences, proving that our results are stable.

The sensitivity and specificity of $P R D M 2$ downregulation in solid tumor were also assessed in order to investigate its potential as a diagnostic biomarker. A split forest plot displaying the sensitivity and specificity of the included studies is shown in Fig. 6. As demonstrated in the summary receiver operating characteristic (SROC) curve (Fig. 7), the summary sensitivity and specificity of decreased PRDM2 gene expression in solid tumor is $84 \%$ (95\% CI 39-98\%) and $86 \%$ (95\% CI 71-94\%), respectively. This result is in favor of $P R D M 2$ downregulation as a potential diagnostic biomarker. However, the confidence interval for PRDM2 downregulation is wide, suggesting that there is marked imprecision. This was later confirmed on TSA (Fig. 8). In Fig. 8, the line representing the cumulative Z-curve failed to cross the significance boundary and did not reach the required number of studies which is 7743 . Therefore, it can be concluded that

Peer) reviewing PDF | (2019:12:44160:1:1:NEW 25 Feb 2020) 
242 the usage of PRDM2 downregulation as a diagnostic biomarker in solid tumor is still

243 inconclusive.

244

245 Quality Assessment of Included Studies

246 The quality of the included studied was evaluated using the QUADAS-2 tool, and a summary of

247 the results can be viewed in Table 3. As shown in Table 3, in the index test domain there are four 248 studies (Ge et al. 2015; Geli et al. 2005; Jiang et al. 1999; Tan et al. 2018) having an unclear risk

249 of bias. These four studies did not directly state whether the index test (gene expression analysis)

250 was interpreted independently from the reference standard (histopathological examination).

251 Thus, we decided that unclear was most fit as the risk of bias. One of the studies, Jiang et al.

252 (1999) also had missing information on how the patients were recruited, leading to an unclear

253 risk of bias for one other domain. In general, the quality of the included studies was robust,

254 ensuring the reliability of our systematic review and meta-analysis.

255

256

257

258

259

260

261

262

263

264

265

266

267

268

269

270

271

272

273

274

275

276

277

278

279

280

\section{Confidence in Cumulative Evidence}

By assessing five domains, including the risk of bias (by using the results from QUADAS-2 risk of bias assessment), indirectness, inconsistency, imprecision (by using the results from TSA) and risk of publication bias, a GRADE evidence profile was constructed as shown in Table 4. To be noted, all of the included studies used diagnostic accuracy test as their design, whereby all of the samples and controls will undergo both the index test and reference standard. Ideally, diagnostic studies should randomize which of the samples and controls will undergo the index test only and which will undergo the reference standard only. Hence, this made the design susceptible to indirectness. In addition, most of the included studies have wide confidence interval and inconclusive TSA results. Thus, serious was placed in the imprecision domain. As for publication bias, since the number of included studies is $<10$, publication bias could not be evaluated. Unfortunately, this does not entirely rule out the possibility of publication bias being present in our study, and thus we decided to downgrade the quality of evidence further. Overall, we have very low confidence in the pooled estimates obtained for our meta-analysis.

\section{Discussion}

In this study, we have successfully generated the first meta-analysis that investigated the potential of $P R D M 2$ downregulation as a diagnostic biomarker in solid tumor. Compared to previous primary studies on $P R D M 2$ thus far, we investigated the significance of $P R D M 2$ with solid tumor on the level of a review. This includes the evaluation of quality assessment, data reliability and confidence in cumulative evidence, proving that our study was more comprehensive.

Meta-regression, funnel plot and Deek's test were not performed due to the small number of studies obtained. Due to the inability to confirm the presence of publication bias, we also could 
281

282

283

284

285

286

287

288

289

290

291

292

293

294

295

296

297

298

299

300

301

302

303

304

305

306

307

308

309

310

311

312

313

314

315

316

317

318

319

320

not perform trim and fill method. Since our results indicated that there was no heterogeneity in the studies used, a subgroup analysis was not required.

In line with previous studies, our results demonstrated that PRDM2 downregulation occurs in ovarian cancer, esophageal squamous cell carcinoma, hepatoma and lung cancer. According to Sorrentino et al. (2018), PRDM2 downregulation has also been reported in neuroblastoma, breast cancers, melanoma, parathyroid adenoma and Merkel cell carcinoma. However, our included studies did not investigate those solid tumors. Another notable difference is the inconclusive results linking PRDM2 downregulation with cancer stage and grade even though PRDM2 downregulation has been associated with cancer progression (Sun et al. 2011). A possible explanation for these inconsistencies might be due to the fact that our study only accepted human studies, and thus limited the possibility of encountering such studies. Interestingly, all of the individual studies did not have a standardised baseline to define PRDM2 downregulation. Although this could lead to possible heterogeneity, our study demonstrated otherwise.

Following these findings, an important question to address is whether PRDM2 downregulation could be used as a diagnostic biomarker in solid tumor. As described above, the high sensitivity and specificity of $P R D M 2$ downregulation suggested its potential as a diagnostic biomarker. However, these values have wide confidence intervals and inconclusive TSA results, implying there was marked imprecision (Chai-Adisaksopha et al. 2016; Tan \& Tan 2010). Thus, the use of PRDM2 downregulation as a diagnostic biomarker is still inconclusive. This imprecision might be due to the small number of sample and controls used in the individual studies or low variability in the subjects used (Carlson \& Morrison 2009). In addition, there was also a vast difference between the sample and control size, whereby the sample size is much larger. We believe that this was because some of the studies did not obtain their sample and control from the same subject. This made acquirement of control samples, such as normal ovaries or normal adrenal cells, much more difficult when compared to pathological samples that are readily retrieved for examination. Although our present study could not fully prove the potential of PRDM2 downregulation as a diagnostic biomarker due to its imprecision, it is important to highlight that these results can potentially improve with the addition of new studies. This has been proven by our TSA results whereby the line representing the cumulative Z-curve did not cross the futility boundary.

Another issue that should be addressed in the future is whether the quality of our evidence is satisfying enough. The quality of evidence is judged based on five domains: risk of bias, indirectness, inconsistency, imprecision and publication bias. It should be noted that all of the studies used in this review are diagnostic accuracy studies which are considered a proxy to randomised-controlled trials. Hence, indirectness is present, and this could lead to overestimation of sensitivity and specificity, resulting in the downgrading of the quality of evidence (Schmidt \& Factor 2013). As discussed before, imprecision is present, and publication bias could not be 
321

322

323

324

325

326

327

328

329

330

331

332

333

334

335

336

337

338

339

340

341

342

343

344

345

346

347

348

349

350

351

352

353

\section{Abbrevations}

355 CI: Confidence interval

356 Df: Degree of freedom

357 F: Female

358

359

360 added. studies.

\section{Conclusions}

FN: False negative

FP: False positive

assessed, leading to further downgrading. Together, these three domains led to the downgrading of the quality of evidence from high to very low. Although there is very low confidence for our results, it is important to highlight once again that these results can improve if new studies are

Limitations of our study are the lack of RCTs as part of our included studies which made it difficult to evaluate the internal validity of our results (Carlson \& Morrison 2009). As mentioned before, our study also lacks clinicopathological data in order to assess the potential of PRDM2 further. Interestingly, none of the included studies investigated $P R D M 2$ gene expression in the same type of solid tumor. Hence, we were unable to evaluate in which type of solid tumor is PRDM2 downregulation most suitable to be used as a biomarker. Furthermore, there was no standardised baseline among studies. Another limitation of this study involves the issue of only using studies written in English, leading to the possibility of language bias. Most of the individual studies have a wide confidence interval and inconclusive TSA results, indicating there is insufficient knowledge about the effect and that further research should be done. Based on the points above, it can be concluded that a major source of limitation is due to the small number of

In conclusion, our review suggested that $P R D M 2$ gene expression is decreased or downregulated in solid tumor. Due to insufficient data, we are unable to determine the relationship between PRDM2 downregulation and clinicopathological data. Although the sensitivity and specificity of PRDM2 downregulation are imprecise, its high values, in addition to the evidence that suggested PRDM2 downregulation in solid tumor, hinted that it might still have a potential to be used as a diagnostic biomarker. Furthermore, its imprecision could potentially be solved through the addition of new studies. Thus, we suggest more research to be conducted, especially those with RCT as their design, to fully elucidate the potential of $P R D M 2$ downregulation in solid tumor. More study is urgently needed to determine a standardised baseline for PRDM2 downregulation level. We would also recommend more research regarding the relationship between PRDM2 gene expression with clinicopathological data to further evaluate the potential of PRDM2 gene expression in solid tumor. Finally, once there is sufficient data available, we suggest a new systematic review and meta-analysis to be done in order to renew the findings of our study.

GRADE: Grading of recommendations, assessment, development, and evaluations 
361 IHC: Immunohistochemistry

362 LAC: Lung adenocarcinoma

363 LSCC: Lung squamous cell carcinoma

364 M: Male

365 M-H: Mantel-Haenszel

366 ND: Not determined

367 OR: Odds ratio

368 PRDM2: Positive regulatory/su(var)3-9, enhancer-of-zeste and trithorax domain 2

369 PRISMA: Preferred reporting items for systematic reviews and meta-analyses

370 PROSPERO: International prospective register of systematic reviews

371 qRT-PCR: Quantitative reverse transcription-polymerase chain reaction

372 QUADAS-2: Quality assessment of diagnostic accuracy studies - 2

373 RCC: Renal cell carcinoma

374 REM: Random effects model

375 RR: Risk ratio

376 RT-PCR: Reverse transcription-polymerase chain reaction

377 SROC: Summary receiver operating characteristic

378 TN: True negative

379 TP: True positive

380 TSA: Trial sequential analysis

381 TSG: Tumor suppressor gene

382

383 Acknowledgements

384 The authors would like to acknowledge School of Medicine and Health Sciences, Atma Jaya 385 Catholic University of Indonesia for all the support for this research project.

Reference

388

389

390

391

392

393

394

395

396

397
Akahira J, Suzuki F, Suzuki T, Miura I, Kamogawa N, Miki Y, Ito K, Yaegashi N, and Sasano H. 2007. Decreased expression of RIZ1 and its clinicopathological significance in epithelial ovarian carcinoma: correlation with epigenetic inactivation by aberrant DNA methylation. Pathol Int 57:725-733. 10.1111/j.1440-1827.2007.02169.x

Baker WL, White CM, Cappelleri JC, Kluger J, and Coleman CI. 2009. Understanding heterogeneity in meta-analysis: the role of meta-regression. Int J Clin Pract 63:1426-1434. $10.1111 / \mathrm{j} .1742-1241.2009 .02168 . \mathrm{x}$

Bray F, Ferlay J, Soerjomataram I, Siegel RL, Torre LA, and Jemal A. 2018. Global cancer statistics 2018: GLOBOCAN estimates of incidence and mortality worldwide for 36 cancers in 185 countries. CA Cancer J Clin 68:394-424. 10.3322/caac.21492 
398 Carlson MDA, and Morrison RS. 2009. Study design, precision, and validity in observational

399 studies. J Palliat Med 12:77-82. 10.1089/jpm.2008.9690

400 Chai-Adisaksopha C, Thorlund K, and Iorio A. 2016. Interpreting trial sequential analysis.

401 Transfusion 56:2918-2922. 10.1111/trf.13910

402 Cheng HY, Gao Y, and Lou G. 2010. DNA methylation of the RIZ1 tumor suppressor gene plays 403 an important role in the tumorigenesis of cervical cancer. Eur J Med Res 15:20-24.

404 10.1186/2047-783x-15-1-20

405 Cui Y, Ding M, Dong S, Wang Y, and Zhang P. 2016. The unusual yin-yang fashion of 406 RIZ1/RIZ2 contributes to the progression of esophageal squamous cell carcinoma. Open Life Sci 407 11:136. 10.1515/biol-2016-0019

408 Deeks JJ, Macaskill P, and Irwig L. 2005. The performance of tests of publication bias and other 409 sample size effects in systematic reviews of diagnostic test accuracy was assessed. J Clin 410 Epidemiol 58:882-893. 10.1016/j.jclinepi.2005.01.016

411 Diamandis EP. 2012. The failure of protein cancer biomarkers to reach the clinic: why, and what 412 can be done to address the problem? BMC Medicine 10:87. 10.1186/1741-7015-10-87

413 Dong SW, Cui YT, Zhong RR, Liang DC, Liu YM, Wang YG, He Z, Wang S, Liang SJ, and 414 Zhang P. 2012. Decreased expression of retinoblastoma protein-interacting zinc-finger gene 1 in 415 human esophageal squamous cell cancer by DNA methylation. Clin Lab 58:41-51.

416 Duval S, and Tweedie R. 2000. Trim and fill: A simple funnel-plot-based method of testing and 417 adjusting for publication bias in meta-analysis. Biometrics 56:455-463. 10.1111/j.0006418 341x.2000.00455.x

419 Ge P, Yu X, Wang ZC, and Lin J. 2015. Aberrant Methylation of the 1p36 Tumor Suppressor 420 Gene RIZ1 in Renal Cell Carcinoma. Asian Pac J Cancer Prev 16:4071-4075.

$421 \quad 10.7314 /$ apjcp.2015.16.9.4071

422 Geli J, Nord B, Frisk T, Edstrom Elder E, Ekstrom TJ, Carling T, Backdahl M, and Larsson C. 423 2005. Deletions and altered expression of the RIZ1 tumour suppressor gene in 1p36 in 424 pheochromocytomas and abdominal paragangliomas. Int J Oncol 26:1385-1391.

425 10.3892/ijo.26.5.1385

426 Goossens N, Nakagawa S, Sun X, and Hoshida Y. 2015. Cancer biomarker discovery and 427 validation. Transl Cancer Res 4:256-269. 10.3978/j.issn.2218-676X.2015.06.04

428 Higgins J, and Green S. 2011. Cochrane Handbook for Systematic Reviews of Interventions 429 Version 5.1.0 (updated March 2011). The Cochrane Collaboration.

430 Higgins JP, Thompson SG, Deeks JJ, and Altman DG. 2003. Measuring inconsistency in meta431 analyses. Bmj 327:557-560. 10.1136/bmj.327.7414.557 
432 Jiang G, Liu L, Buyse IM, Simon D, and Huang S. 1999. Decreased RIZ1 expression but not 433 RIZ2 in hepatoma and suppression of hepatoma tumorigenicity by RIZ1. Int J Cancer 83:541434 546. 10.1002/(sici)1097-0215(19991112)83:4<541::aid-ijc17>3.0.co;2-f

435 Johansson P, Klein-Hitpass L, Choidas A, Habenberger P, Mahboubi B, Kim B, Bergmann A, 436 Scholtysik R, Brauser M, Lollies A, Siebert R, Zenz T, Dührsen U, Küppers R, and Dürig J. 437 2018. SAMHD1 is recurrently mutated in T-cell prolymphocytic leukemia. Blood Cancer J 8:11. 438 10.1038/s41408-017-0036-5

439 Lal G, Padmanabha L, Smith BJ, Nicholson RM, Howe JR, O'Dorisio MS, and Domann FE, Jr. 440 2006. RIZ1 is epigenetically inactivated by promoter hypermethylation in thyroid carcinoma.

441 Cancer 107:2752-2759. 10.1002/cncr.22325

442 Michalak EM, and Visvader JE. 2016. Dysregulation of histone methyltransferases in breast 443 cancer - Opportunities for new targeted therapies? Mol Oncol 10:1497-1515.

444 10.1016/j.molonc.2016.09.003

445 Moher D, Liberati A, Tetzlaff J, Altman DG, and Group P. 2009. Preferred reporting items for 446

447

448

449

450

451

452 systematic reviews and meta-analyses: the PRISMA statement. PLoS Med 6:e1000097e1000097. 10.1371/journal.pmed.1000097

National Institute for Health Research. PROSPERO: International prospective register for systematic reviews. Available at https://www.crd.york.ac.uk/prospero/ (accessed 22 May 2019).

Oshimo Y, Oue N, Mitani Y, Nakayama H, Kitadai Y, Yoshida K, Chayama K, and Yasui W. 2004. Frequent epigenetic inactivation of RIZ1 by promoter hypermethylation in human gastric carcinoma. Int J Cancer 110:212-218. 10.1002/ijc.20090

453 Pandzic T, Rendo V, Lim J, Larsson C, Larsson J, Stoimenov I, Kundu S, Ali MA, Hellström M, 454 He L, Lindroth AM, and Sjöblom T. 2017. Somatic PRDM2 c.4467delA mutations in colorectal cancers control histone methylation and tumor growth. Oncotarget 8:98646-98659. 10.18632/oncotarget.21713

457 Rossi V, Staibano S, Abbondanza C, Pasquali D, De Rosa C, Mascolo M, Bellastella G, Visconti 458 D, De Bellis A, Moncharmont B, De Rosa G, Puca GA, Bellastella A, and Sinisi AA. 2009. Expression of RIZ1 protein (Retinoblastoma-interacting zinc-finger protein 1) in prostate cancer epithelial cells changes with cancer grade progression and is modulated in vitro by DHT and E2. J Cell Physiol 221:771-777. 10.1002/jcp.21920

462

463 464 465

466 467
Sakurada K, Furukawa T, Kato Y, Kayama T, Huang S, and Horii A. 2001. RIZ, the retinoblastoma protein interacting zinc finger gene, is mutated in genetically unstable cancers of the pancreas, stomach, and colorectum. Genes Chromosome Canc 30:207-211. 10.1002/10982264(2000)9999:9999<::AID-GCC1080>3.0.CO;2-V

Schiffman JD, Fisher PG, and Gibbs P. 2015. Early detection of cancer: past, present, and future. Am Soc Clin Oncol Educ Book:57-65. 10.14694/EdBook_AM.2015.35.57 
468 Schmidt RL, and Factor RE. 2013. Understanding sources of bias in diagnostic accuracy studies. 469 Arch Pathol Lab Med 137:558-565. 10.5858/arpa.2012-0198-RA

470 Schünemann H, Brożek J, Guyatt G, and Oxman A. 2013. GRADE Handbook for Grading 471 Quality of Evidence and Strength of Recommendations (updated October 2013). The GRADE 472 Working Group.

473 Sorrentino A, Rienzo M, Ciccodicola A, Casamassimi A, and Abbondanza C. 2018. Human 474 PRDM2: Structure, function and pathophysiology. Biochim Biophys Acta Gene Regul Mech. 475 10.1016/j.bbagrm.2018.06.002

476 Sun W, Qiao L, Liu Q, Chen L, Ling B, Sammynaiken R, and Yang J. 2011. Anticancer activity 477 of the PR domain of tumor suppressor RIZ1. Int J Med Sci 8:161-167. 10.7150/ijms.8.161

478 Tan S-X, Hu R-C, Xia Q, Tan Y-L, Liu J-J, Gan G-X, and Wang L-1. 2018. The methylation 479 profiles of PRDM promoters in non-small cell lung cancer. Onco Targets Ther 11:2991-3002. $480 \quad 10.2147 /$ OTT.S156775

481 Tan SH, and Tan SB. 2010. The Correct Interpretation of Confidence Intervals. PoSH 19:276482 278. 10.1177/201010581001900316

483 Tan SX, Hu RC, Liu JJ, Tan YL, and Liu WE. 2014. Methylation of PRDM2, PRDM5 and 484 PRDM16 genes in lung cancer cells. Int J Clin Exp Pathol 7:2305-2311.

485 Wetterslev J, Jakobsen JC, and Gluud C. 2017. Trial Sequential Analysis in systematic reviews 486 with meta-analysis. BMC Med Res Methodol 17:39. 10.1186/s12874-017-0315-7

487 Whiting PF, Rutjes AW, Westwood ME, Mallett S, Deeks JJ, Reitsma JB, Leeflang MM, Sterne 488 JA, and Bossuyt PM. 2011. QUADAS-2: a revised tool for the quality assessment of diagnostic 489 accuracy studies. Ann Intern Med 155:529-536. 10.7326/0003-4819-155-8-201110180-00009

490 World Health Organization. 2017. Guide to cancer early diagnosis. Geneva: World Health 491 Organization.

492 World Health Organization. 2018. Cancer. Available at https://www.who.int/health493 topics/cancer\#tab=tab 1 (accessed 12 Apr 2019).

494 Wu S, Yang Z, Ye R, An D, Li C, Wang Y, Wang Y, Huang Y, Liu H, Li F, He L, Sun D, Yu Y, 495 Li Q, Huang P, Zhang M, Zhao X, Bi T, Zhuang X, Zhang L, Lu J, Sun X, Zhou F, Liu C, Yang 496 G, Hou Y, Fan Z, and Cai Z. 2016. Novel variants in MLL confer to bladder cancer recurrence 497 identified by whole-exome sequencing. Oncotarget 7:2629-2645. 10.18632/oncotarget.6380

498 Yang T, Ren C, Jiang A, Yu Z, Li G, Wang G, and Zhang Q. 2017. RIZ1 is regulated by 499 estrogen and suppresses tumor progression in endometrial cancer. Biochem Biophys Res 500 Commun 489:96-102. 10.1016/j.bbrc.2017.05.095 
501 Zhang C, Li J, Huang T, Duan S, Dai D, Jiang D, Sui X, Li D, Chen Y, Ding F, Huang C, Chen 502 G, and Wang K. 2016. Meta-analysis of DNA methylation biomarkers in hepatocellular 503 carcinoma. Oncotarget 7:81255-81267. 10.18632/oncotarget.13221

504 Zhang C, Zhu Q, He H, Jiang L, Qiang Q, Hu L, Hu G, Jiang Y, Ding X, and Lu Y. 2015. RIZ1: 505 a potential tumor suppressor in glioma. BMC Cancer 15:990. 10.1186/s12885-015-2023-1 506 
Figure 1

\section{PRISMA flow diagram for selection of included studies.}

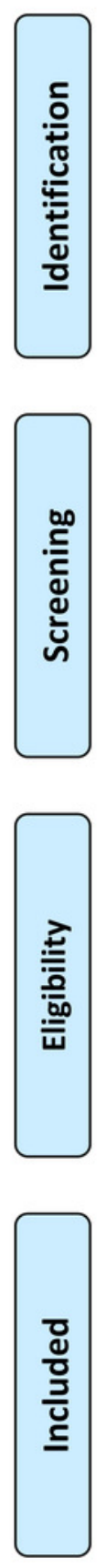

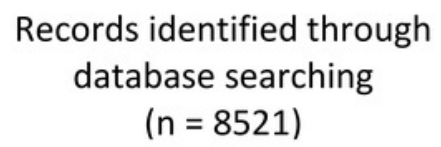

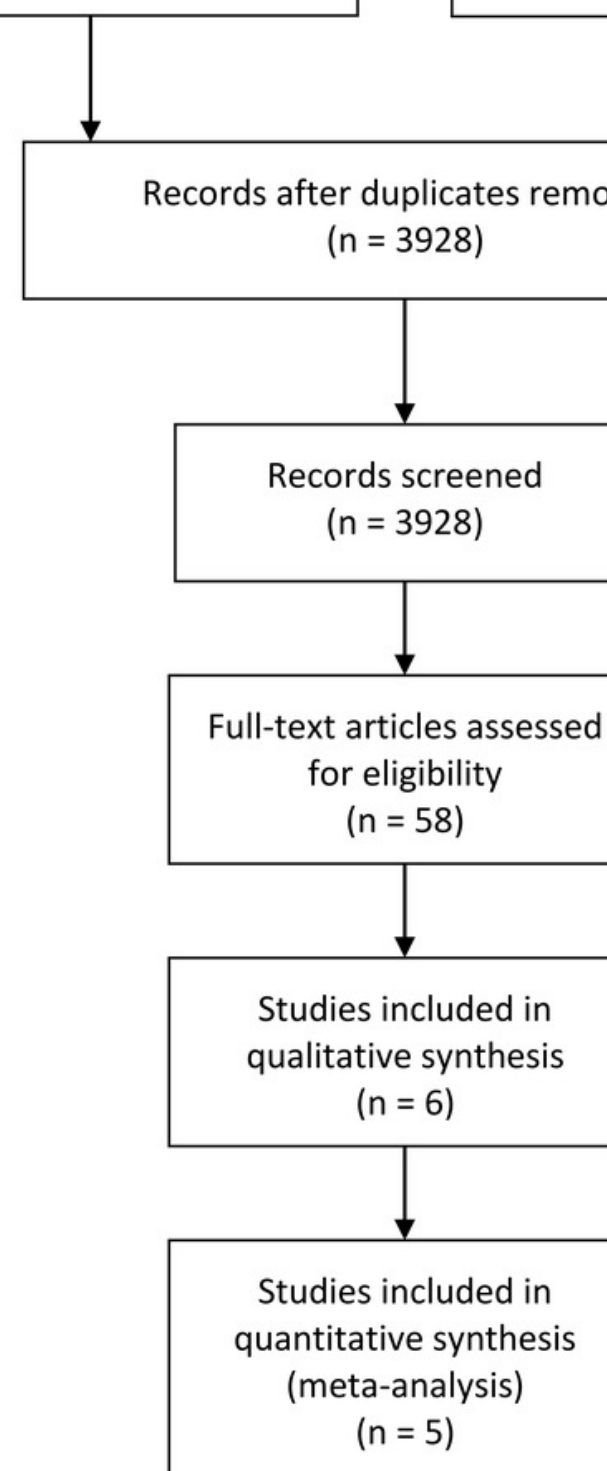

Additional records identified through other sources

$(n=0)$
Records excluded $(n=3870)$ : not relevant $(n=3449)$, nonEnglish $(n=419)$, abstract unavailable $(n=1)$, review $(n=1)$

Full-text articles excluded $(n=52)$ : ineligible $(n=39)$, in vivo and/or in vitro $(n=7)$, unsuitable method $(n=4)$, non-English $(n=1)$, review $(n=1)$ 


\section{Figure 2}

Forest plot of PRDM2 downregulation in solid tumors and control.

Studies with notable weights are Tan et al. (2018) (46.2\%) and Dong et al. (2012) (31.2\%).

The results from this forest plot demonstrated that PRDM2 downregulation occurs more often in solid tumor when compared to control ( $R R 4.29,95 \% \mathrm{Cl} 2.58-7.13, \mathrm{P}<0.00001)$. There was no significant heterogeneity in this analysis $\left(X^{2}=2.85, I^{2}=0 \%\right)$. The horizontal line represents $95 \% \mathrm{Cl}$. The blue box is the result of each individual study. The black diamond at the bottom of the plot is the pooled analysis of all studies. $\mathrm{Cl}=$ Confidence interval. $\mathrm{df}=$ Degree of freedom. $\mathrm{I}^{2}=$ Test of heterogeneity. $\mathrm{M}-\mathrm{H}=$ Mantel-Haenszel.

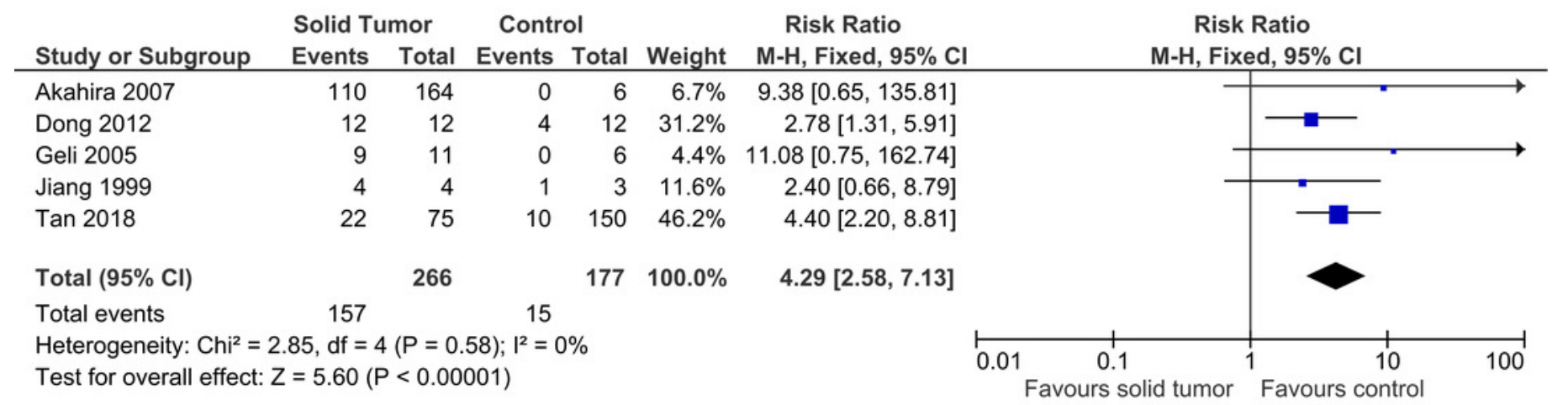




\section{Figure 3}

Sensitivity analysis to compare the use of all studies with deletion of a study.

The deleted study, Jiang et al. (1999), is a study that has the most questionable results based on the risk of bias assessment. There was a significant result for both analyses: (A) Without deletion of Jiang et al. (1999): RR 4.29, 95\% Cl 2.58-7.13, $\mathrm{P}<0.00001, \mathrm{X}^{2}=2.85, \mathrm{P}<0.58, \mathrm{I}^{2}=$ 0\%; (B) With deletion of Jiang et al. (1999): RR 4.53, 95\% Cl 2.63-7.82, $\mathrm{P}<0.00001, \mathrm{X}^{2}=2.33$, $P<0.51, I^{2}=0 \%$. The deletion of Jiang et al. (1999) increased RR by 1.1 times higher with the $95 \% \mathrm{Cl} 1.2$ times wider. The deletion of study also slightly lowered heterogeneity. This sensitivity analysis proved that the results were stable. The horizontal line represents $95 \%$ $\mathrm{Cl}$. The blue box is the result of each individual study. $\mathrm{Cl}=$ Confidence interval. $\mathrm{df}=$ Degree of freedom. $\mathrm{I}^{2}=$ Test of heterogeneity. $\mathrm{M}-\mathrm{H}=$ Mantel-Haenszel. 
A

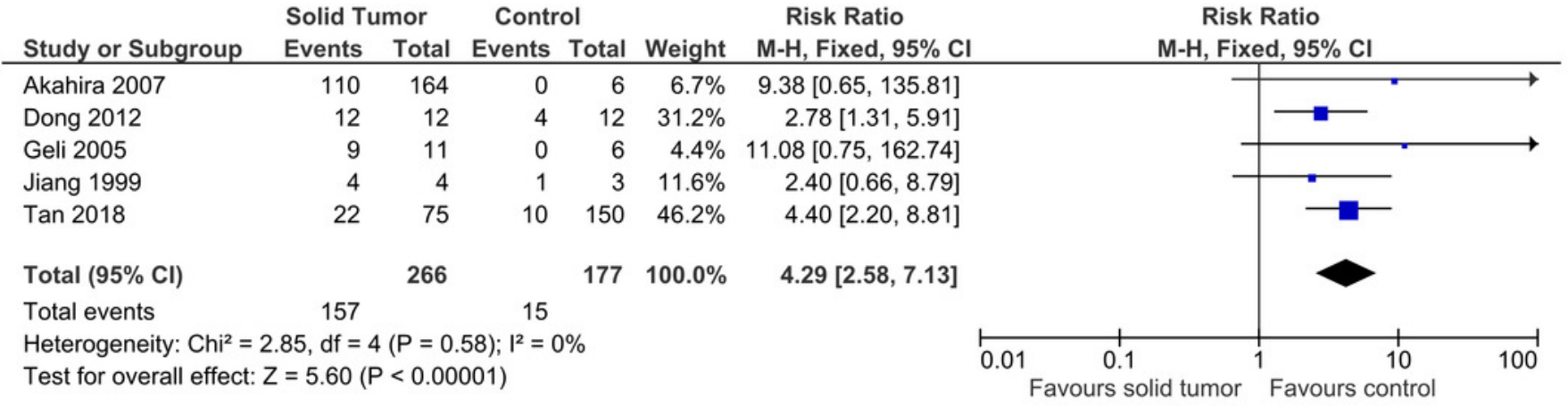

B

\begin{tabular}{|c|c|c|c|c|c|c|c|c|c|}
\hline \multirow[b]{2}{*}{ Study or Subgroup } & \multicolumn{2}{|c|}{ Solid Tumor } & \multicolumn{2}{|c|}{ Control } & \multirow{3}{*}{$\begin{array}{r}\text { Weight } \\
7.5 \%\end{array}$} & \multirow{2}{*}{$\begin{array}{c}\text { Risk Ratio } \\
\text { M-H, Fixed, } 95 \% \mathrm{Cl}\end{array}$} & \multirow{2}{*}{\multicolumn{3}{|c|}{$\begin{array}{c}\text { Risk Ratio } \\
\text { M-H, Fixed, } 95 \% \text { Cl }\end{array}$}} \\
\hline & Events & Total & Events & Total & & & & & \\
\hline Akahira 2007 & 110 & 164 & 0 & 6 & & $9.38[0.65,135.81]$ & & & \\
\hline Dong 2012 & 12 & 12 & 4 & 12 & $35.3 \%$ & $2.78[1.31,5.91]$ & & $\longrightarrow$ & \\
\hline Geli 2005 & 9 & 11 & 0 & 6 & $5.0 \%$ & $11.08[0.75,162.74]$ & & & \\
\hline Tan 2018 & 22 & 75 & 10 & 150 & $52.3 \%$ & $4.40[2.20,8.81]$ & & $\rightarrow$ & \\
\hline Total $(95 \% \mathrm{Cl})$ & & 262 & & 174 & $100.0 \%$ & $4.53[2.63,7.82]$ & & & \\
\hline Total events & 153 & & 14 & & & & & & \\
\hline $\begin{array}{l}\text { Heterogeneity: } \mathrm{Chi}^{2}= \\
\text { Test for overall effect }\end{array}$ & $\begin{array}{l}.33, \mathrm{df}=3 \\
=5.43(\mathrm{P}\end{array}$ & $\begin{array}{l}(P=0 . \\
<0.00\end{array}$ & $\begin{array}{l}51) ;\left.\right|^{2}=0 \\
001)\end{array}$ & & & & $0.01 \quad 0.1$ & & 100 \\
\hline
\end{tabular}




\section{Figure 4}

Sensitivity analysis to compare the use of Risk Ratio (RR) with Odds Ratio (OR).

There was a significant result for both analyses: (A) RR: RR 4.29, 95\% Cl 2.58-7.13, $\mathrm{P}<0.00001$; (B) OR: OR 9.62, 95\% Cl 4.82-19.19, $\mathrm{P}<0.00001$ ). The use of $\mathrm{OR}$ gave a result two times higher with the $95 \% \mathrm{Cl}$ three times wider when compared to RR. RR had a slightly lower heterogeneity when compared to OR $\left(R R: X^{2}=2.58, P<0.58, I^{2}=0 \% ; O R: X^{2}=4.06\right.$, $\left.P<0.40, I^{2}=1 \%\right)$. This sensitivity analysis proved that the results were stable. The horizontal line represents $95 \% \mathrm{Cl}$. The blue box is the result of each individual study. The black diamond at the bottom of the plot is the pooled analysis of all studies. $\mathrm{Cl}=$ Confidence interval. $\mathrm{df}=$ Degree of freedom. $\mathrm{I}^{2}=$ Test of heterogeneity. $\mathrm{M}-\mathrm{H}=$ Mantel-Haenszel. 
A

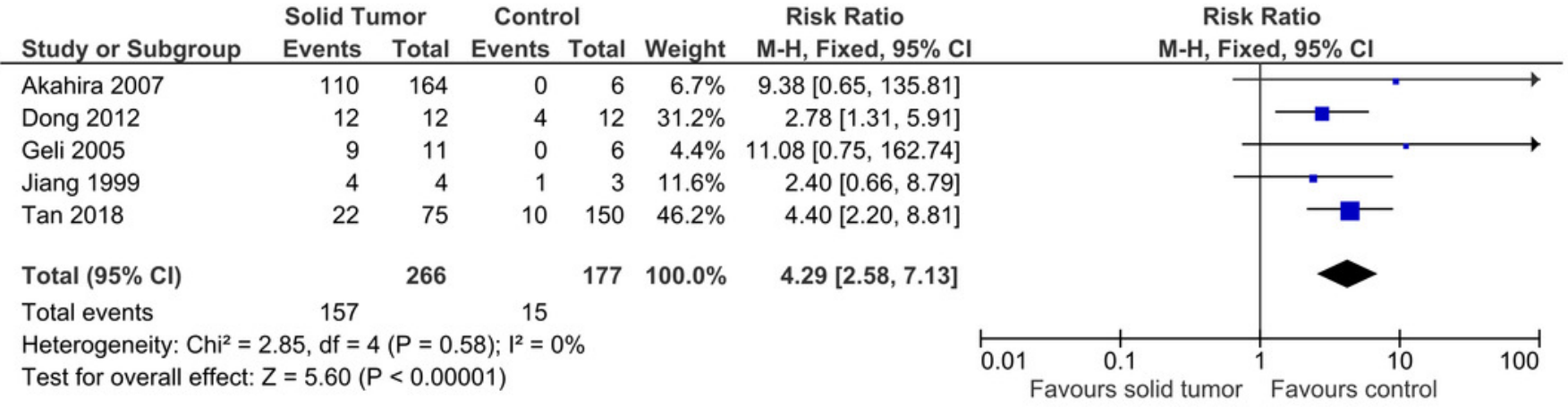

B

\begin{tabular}{|c|c|c|c|c|c|c|c|c|c|}
\hline \multirow[b]{2}{*}{ Study or Subgroup } & \multicolumn{2}{|c|}{ Solid Tumor } & \multicolumn{2}{|c|}{ Control } & \multirow[b]{2}{*}{ Weight } & \multirow{2}{*}{$\begin{array}{l}\text { Odds Ratio } \\
\text { M-H, Fixed, } 95 \% \mathrm{Cl}\end{array}$} & \multirow{2}{*}{\multicolumn{3}{|c|}{$\begin{array}{c}\text { Odds Ratio } \\
\text { M-H, Fixed, } 95 \% \mathrm{Cl}\end{array}$}} \\
\hline & Events & Total & & Total & & & & & \\
\hline Akahira 2007 & 110 & 164 & 0 & 6 & $5.8 \%$ & $26.36[1.46,476.49]$ & & & $\longrightarrow$ \\
\hline Dong 2012 & 12 & 12 & 4 & 12 & $3.1 \%$ & $47.22[2.24,996.02]$ & & & $\longrightarrow$ \\
\hline Geli 2005 & 9 & 11 & 0 & 6 & $2.4 \%$ & $49.40[2.02,1207.15]$ & & & $\longrightarrow$ \\
\hline Jiang 1999 & 4 & 4 & 1 & 3 & $3.0 \%$ & $15.00[0.43,524.53]$ & & & \\
\hline Tan 2018 & 22 & 75 & 10 & 150 & $85.7 \%$ & $5.81[2.58,13.08]$ & & & \\
\hline Total $(95 \% \mathrm{Cl})$ & & 266 & & 177 & $100.0 \%$ & $9.62[4.82,19.19]$ & & & \\
\hline Total events & 157 & & 15 & & & & & & \\
\hline $\begin{array}{l}\text { Heterogeneity: } \mathrm{Chi}^{2}= \\
\text { Test for overall effect }\end{array}$ & $\begin{array}{l}.06, \mathrm{df}= \\
=6.43(\end{array}$ & $\left\{\begin{array}{l}(P=0 \\
<0.00\end{array}\right.$ & $\begin{array}{l}\text { 40); } I^{2}=1 \\
011)\end{array}$ & & & & 0.1 & 1 & 100 \\
\hline
\end{tabular}




\section{Figure 5}

Sensitivity analysis to compare the use of Fixed Effects Model (FEM) with Random Effects Model (REM).

There was a significant result for both analyses: (A) FEM: RR 4.29, 95\% Cl 2.58-7.13, $\mathrm{P}<0.00001$; (B) REM: RR 3.61, 95\% Cl 2.28-5.72, $\mathrm{P}<0.00001$. FEM increased RR by 1.2 times higher with $95 \% \mathrm{Cl} 1.3$ times wider. This sensitivity analysis proved that the results were stable. The horizontal line represents $95 \% \mathrm{Cl}$. The blue box is the result of each individual study. The black diamond at the bottom of the plot is the pooled analysis of all studies. $\mathrm{Cl}=$

Confidence interval. $\mathrm{df}=$ Degree of freedom. $\mathrm{I}^{2}=$ Test of heterogeneity. $\mathrm{M}-\mathrm{H}=$ MantelHaenszel. 
A

\begin{tabular}{|c|c|c|c|c|c|c|c|c|c|}
\hline \multirow[b]{2}{*}{ Study or Subgroup } & \multicolumn{2}{|c|}{ Solid Tumor } & \multicolumn{2}{|c|}{ Control } & \multirow[b]{2}{*}{ Weight } & \multirow{2}{*}{$\begin{array}{c}\text { Risk Ratio } \\
\text { M-H, Fixed, } 95 \% \text { CI }\end{array}$} & \multirow{2}{*}{\multicolumn{3}{|c|}{$\begin{array}{c}\text { Risk Ratio } \\
\text { M-H, Fixed, } 95 \% \text { CI }\end{array}$}} \\
\hline & Events & Total & Events & Total & & & & & \\
\hline Akahira 2007 & 110 & 164 & 0 & 6 & $6.7 \%$ & $9.38[0.65,135.81]$ & & & \\
\hline Dong 2012 & 12 & 12 & 4 & 12 & $31.2 \%$ & $2.78[1.31,5.91]$ & & $\longrightarrow-$ & \\
\hline Geli 2005 & 9 & 11 & 0 & 6 & $4.4 \%$ & $11.08[0.75,162.74]$ & & & \\
\hline Jiang 1999 & 4 & 4 & 1 & 3 & $11.6 \%$ & $2.40[0.66,8.79]$ & & & \\
\hline $\operatorname{Tan} 2018$ & 22 & 75 & 10 & 150 & $46.2 \%$ & $4.40[2.20,8.81]$ & & & \\
\hline Total $(95 \% \mathrm{Cl})$ & & 266 & & 177 & $100.0 \%$ & $4.29[2.58,7.13]$ & & & \\
\hline Total events & 157 & & 15 & & & & & & \\
\hline $\begin{array}{l}\text { Heterogeneity: } \mathrm{Chi}^{2}= \\
\text { Test for overall effec }\end{array}$ & $\begin{array}{l}85, \mathrm{df}= \\
=5.60(\end{array}$ & $\begin{array}{l}(P=0 \\
<0.00\end{array}$ & $\begin{array}{l}58) ; 1^{2}=( \\
001)\end{array}$ & & & & 0.01 & r & 100 \\
\hline
\end{tabular}

B

Solid Tumor Control Risk Ratio

Risk Ratio

Study or Subgroup Events Total Events Total Weight M-H, Random, 95\% Cl $\mathrm{M}-\mathrm{H}$, Random, $95 \% \mathrm{Cl}$

\begin{tabular}{|c|c|c|c|c|c|}
\hline Akahira 2007 & 110 & 164 & 0 & 6 & $3.0 \%$ \\
\hline Dong 2012 & 12 & 12 & 4 & 12 & $37.3 \%$ \\
\hline Geli 2005 & 9 & 11 & 0 & 6 & $2.9 \%$ \\
\hline Jiang 1999 & 4 & 4 & 1 & 3 & $12.6 \%$ \\
\hline Tan 2018 & 22 & 75 & 10 & 150 & $44.1 \%$ \\
\hline Total $(95 \% \mathrm{Cl})$ & & 266 & & 177 & 100.0 \\
\hline Total events & 157 & & 15 & & \\
\hline
\end{tabular}

$9.38[0.65,135.81]$

$2.78[1.31,5.91]$

$11.08[0.75,162.74]$

$2.40[0.66,8.79]$

$4.40[2.20,8.81]$

$3.61[2.28,5.72]$

Test for overall effect: $Z=5.45(P<0.00001)$

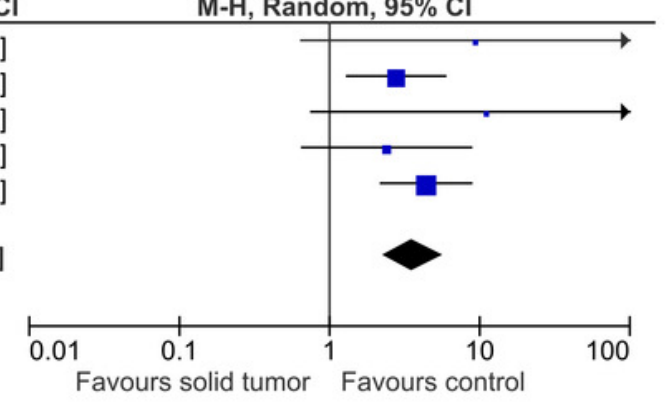




\section{Figure 6}

Forest plot for sensitivity and specificity of decreased PRDM2 gene expression in solid tumor.

Studies that have high sensitivities include Dong et al. (2012) (Sensitivity $1.00,95 \% \mathrm{Cl}$ $0.74-1.00$ ) and jiang et al. (1999) (Sensitivity 1.00, 95\% Cl 0.40-1.00). Studies that have high specificities are Akahira et al. (2007) (Specificity 1.00, 95\% Cl 0.54-1.00) and Geli et al. (2005) (Specificity 1.00, 95\% Cl 0.54-1.00). The horizontal line represents $95 \% \mathrm{Cl}$. The blue box is the result of each individual study. $\mathrm{Cl}=$ Confidence interval. $\mathrm{FN}=$ False negative. $\mathrm{FP}=$ False positive. $\mathrm{TN}=$ True negative. $\mathrm{TP}=$ True positive.

\begin{tabular}{|c|c|c|c|c|c|c|c|c|}
\hline Study & TP & FP & $\mathrm{FN}$ & TN & Sensitivity (95\% Cl) & Specificity $(95 \% \mathrm{CI})$ & Sensitivity $(95 \% \mathrm{Cl})$ & Specificity $(95 \% \mathrm{Cl})$ \\
\hline Akahira 2007 & 110 & 0 & 54 & 6 & $0.67[0.59,0.74]$ & $1.00[0.54,1.00]$ & $\rightarrow$ & \\
\hline Dong 2012 & 12 & 4 & 0 & 8 & $1.00[0.74,1.00]$ & $0.67[0.35,0.90]$ & & \\
\hline Geli 2005 & 9 & 0 & 2 & 6 & $0.82[0.48,0.98]$ & $1.00[0.54,1.00]$ & $=$ & \\
\hline Jiang 1999 & 4 & 1 & 0 & 2 & $1.00[0.40,1.00]$ & $0.67[0.09,0.99]$ & & \\
\hline Tan 2018 & 22 & 10 & 53 & 140 & $0.29[0.19,0.41]$ & $0.93[0.88,0.97]$ & 1 & \\
\hline
\end{tabular}




\section{Figure 7}

Summary receiver operating characteristic (SROC) curve of decreased PRDM2 gene expression in solid tumor.

The overall sensitivity and specificity is $84 \%(95 \% \mathrm{Cl} 39-98 \%)$ and $86 \%$ (95\% Cl $71-94 \%)$, respectively. The calculation of these results can be viewed at Fig. S1. The black circle (summary estimate) represents the summary estimate of sensitivity and specificity. The dotted lines around the summary point represents the $95 \%$ confidence region. The dashed lines represent the $95 \%$ prediction region (the region within which we are $95 \%$ certain that the results of a new study will lie). 


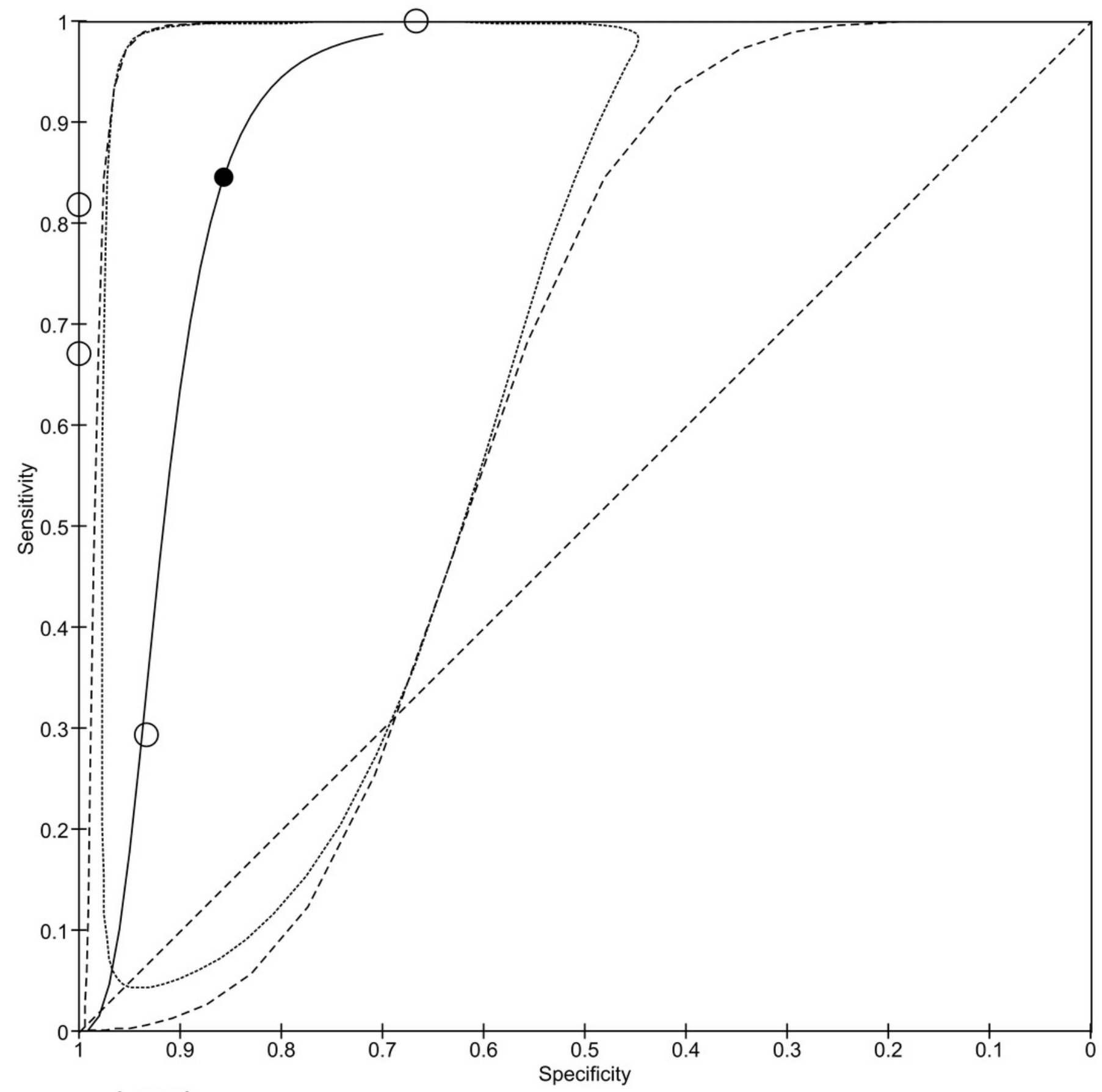

Legend

Study estimate Summary Point ----95\% confidence region - - $95 \%$ prediction region 


\section{Figure 8}

Trial Sequential Analysis (TSA) results of the meta-analysis.

The cumulative Z-curve (blue line) crossed the conventional meta-analysis significance boundary (horizontal red lines at $Z=+1,96$ and $Z=-1,96$ ), confirming that type I error was avoided. However, the cumulative Z-curve has not crossed the trial sequential significance boundary (diagonal red line at the top and bottom of the plot), suggesting that type II error might have not been avoided. Furthermore, the cumulative Z-score has also failed to reach the vertical red line on the right, indicating that this review has not reached the required sample size which is 7743. It is interesting to note that the cumulative Z-curve did not cross the trial sequential futility boundary (triangular red line on the right), implying that the addition of new samples could potentially improve the TSA results. In conclusion, this TSA analysis proved that this meta-analysis still requires more samples in order ensure that type II error was avoided. This is a magnified version of the TSA. The TSA results on a standard scale can be viewed at Fig. S2. 


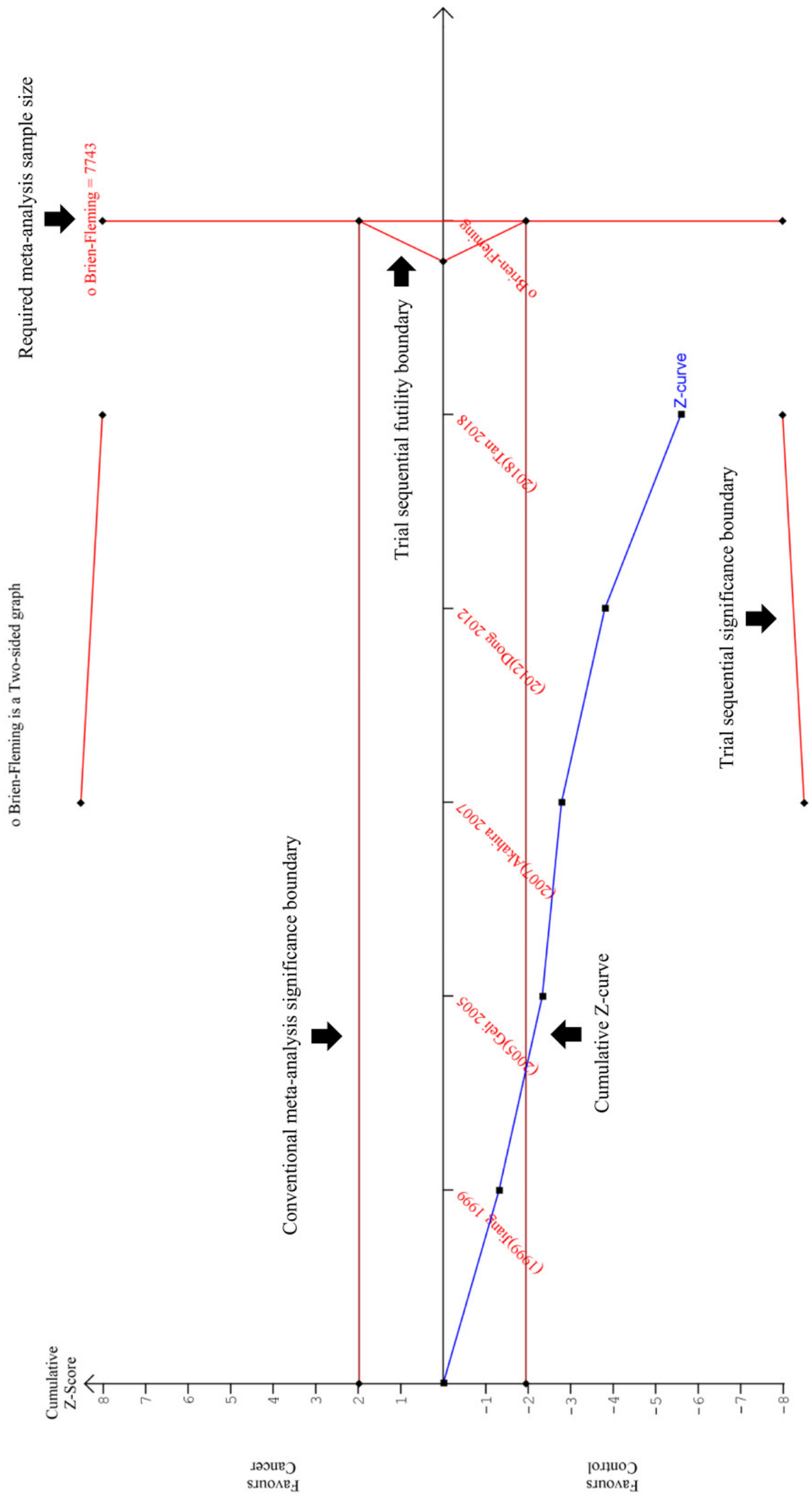

PeerJ reviewing PDF | (2019:12:44160:1:1:NEW 25 Feb 2020) 


\section{Table $\mathbf{1}$ (on next page)}

Study characteristics of studies included in systematic review.

$\mathrm{F}=$ Female $. \mathrm{IHC}=$ Immunohistochemistry $. \mathrm{LAC}=$ Lung adenocarcinoma. $\mathrm{LSCC}=\mathrm{Lung}$ squamous cell carcinoma. $M=$ Male. $N D=$ Not determined. $\mathrm{PRDM} 2=$ Positive Regulatory/Su(var)3-9,Enhancer-of-zeste and Trithorax Domain 2. qRT-PCR = Quantitative reverse transcription-polymerase chain reaction. $\mathrm{RT}-\mathrm{PCR}=$ Reverse transcription-polymerase chain reaction. 


\begin{tabular}{|c|c|c|c|c|c|c|c|c|c|c|c|c|c|c|}
\hline \multirow{3}{*}{ Study } & \multirow{3}{*}{ Country } & \multirow{3}{*}{ Age } & \multirow{3}{*}{ Gender } & \multirow{3}{*}{ Race } & \multirow{3}{*}{ Method } & \multirow{3}{*}{$\begin{array}{l}\text { No. of } \\
\text { sample }\end{array}$} & \multirow{3}{*}{$\begin{array}{l}\text { No. of } \\
\text { control }\end{array}$} & \multicolumn{5}{|c|}{ Cancer } & \multirow{3}{*}{$\begin{array}{c}P R D M 2 \\
\text { expression }\end{array}$} & \multirow{3}{*}{$P$ value } \\
\hline & & & & & & & & \multirow{2}{*}{ Type } & \multicolumn{2}{|c|}{ Stage } & \multicolumn{2}{|c|}{ Differentiation } & & \\
\hline & & & & & & & & & I+II & III+IV & $\begin{array}{c}\text { Well/ } \\
\text { Moderate }\end{array}$ & Poor & & \\
\hline $\begin{array}{l}\text { Akahira et al. } \\
\text { (2007) }\end{array}$ & Japan & $\begin{array}{c}<50 \\
(\mathrm{n}=42 / 67) \\
>=50 \\
(\mathrm{n}=68 / 97)\end{array}$ & ND & Asian & $\mathrm{IHC}$ & 164 & $6^{\mathrm{a}}$ & Ovarian cancer & 69 & 95 & $107^{\mathrm{h}}$ & $36^{\mathrm{h}}$ & Decreased $^{\mathrm{i}}$ & $<0.05$ \\
\hline $\begin{array}{l}\text { Dong et al. } \\
\text { (2012) }\end{array}$ & China & ND & ND & Asian & $\begin{array}{c}\text { RT-PCR } \\
\text { IHC }\end{array}$ & 40 & $40^{\mathrm{b}}$ & $\begin{array}{l}\text { Esophageal squamous } \\
\text { cell carcinoma }\end{array}$ & ND & ND & ND & ND & Decreased $^{\mathrm{i}}$ & $<0.05^{\mathrm{j}}$ \\
\hline $\begin{array}{l}\text { Ge et al. } \\
(2015)\end{array}$ & China & ND & ND & Asian & qRT-PCR & 20 & $20^{\mathrm{c}}$ & Renal cell carcinoma & ND & ND & ND & ND & Decreased $^{\mathrm{i}}$ & $<0.001 \mathrm{k}$ \\
\hline $\begin{array}{l}\text { Geli et al. } \\
\text { (2005) }\end{array}$ & Sweden & ND & $\begin{array}{l}7 \mathrm{M} \\
4 \mathrm{~F}\end{array}$ & Caucasian & qRT-PCR & 11 & $6^{\mathrm{d}}$ & $\begin{array}{l}\text { Pheochromocytoma } \\
(\mathrm{n}=4) \\
\text { Abdominal } \\
\text { paraganglioma }(\mathrm{n}=7)\end{array}$ & ND & ND & ND & ND & Decreased ${ }^{\mathrm{i}}$ & $<0.001^{1}$ \\
\hline $\begin{array}{l}\text { Jiang et al. } \\
\text { (1999) }\end{array}$ & $\begin{array}{l}\text { United } \\
\text { States of } \\
\text { America }\end{array}$ & ND & ND & Caucasian & RT-PCR & 4 & $3^{\mathrm{e}}$ & Hepatoma & ND & ND & ND & ND & Decreased $^{\mathrm{i}}$ & ND \\
\hline $\begin{array}{l}\text { Tan et al. } \\
\text { (2018) }\end{array}$ & China & $\begin{array}{c}<60(\mathrm{n}=30) \\
\quad>=60 \\
(\mathrm{n}=45)\end{array}$ & $\begin{array}{l}56 \mathrm{M} \\
19 \mathrm{~F}\end{array}$ & Asian & $\begin{array}{c}\text { RT-PCR } \\
\text { IHC }\end{array}$ & 75 & $150^{\mathrm{f}}$ & $\begin{array}{l}\operatorname{LSCC}(\mathrm{n}=52) \\
\operatorname{LAC}(\mathrm{n}=23)\end{array}$ & $63^{g}$ & $12 \mathrm{~g}$ & $46^{\mathrm{g}}$ & $29 \mathrm{~g}$ & Decreased $^{i}$ & $<0.05^{\mathrm{m}}$ \\
\hline \multicolumn{8}{|c|}{$\begin{array}{l}\text { a Normal ovaries } \\
\text { b Adjacent non-cancerous tissue } \\
\text { c Adjacent non-malignant renal tissue } \\
\text { d Normal adrenal cells } \\
\text { e Normal liver tissue } \\
\text { f Tumor adjacent tissue and distant lung tissue } \\
{ }^{\mathrm{g}} \text { Classification based on International Association for the Study of Lung Cancer } 2009\end{array}$} & \multicolumn{7}{|c|}{$\begin{array}{l}\text { h Classification based on universal grading system for ovarian epithelian cancer } \\
{ }^{\mathrm{i}} \text { PRDM2 expression level is decreased when compared to control } \\
{ }^{\mathrm{j}} \text { Chi-square test; } \mathrm{X}^{2}=12.00 \\
{ }^{\mathrm{k}} \text { Median fold difference }=0.08 \text { (interquartile range } 0.03-0.50 \text { ) } \\
{ }^{\mathrm{l} W i l c o x o n} \text { matched pair test } \\
\text { m Student's t-test or one-way analysis of variance, followed by Newman-Keuls test }\end{array}$} \\
\hline
\end{tabular}

Table 1: Study characteristics of studies included in systematic review.

$\mathrm{F}=$ Female. $\mathrm{IHC}=$ Immunohistochemistry. $\mathrm{LAC}=$ Lung adenocarcinoma. $\mathrm{LSCC}=$ Lung squamous cell carcinoma. $\mathrm{M}=$ Male. $\mathrm{ND}=$ Not determined. PRDM2 = Positive Regulatory/Su(var)3-9, Enhancer-of-zeste and Trithorax Domain 2. qRT-PCR = Quantitative reverse transcription-polymerase chain reaction. $\mathrm{RT}-\mathrm{PCR}=$ Reverse transcription-polymerase chain reaction. 


\section{PeerJ}




\section{Table 2 (on next page)}

Study characteristics of studies included in meta-analysis.

$\mathrm{FN}=$ False negative. $\mathrm{FP}=$ False positive. $\mathrm{IHC}=$ Immunohistochemistry. $\mathrm{LAC}=$ Lung adenocarcinoma. $\mathrm{LSCC}=$ Lung squamous cell carcinoma. $\mathrm{qRT}-\mathrm{PCR}=$ Quantitative reverse transcription-polymerase chain reaction. $\mathrm{TN}=$ True negative. $\mathrm{TP}=$ True positive 


\begin{tabular}{|c|c|c|c|c|c|c|c|c|}
\hline Study & Method & $\begin{array}{c}\text { No. of } \\
\text { sample }\end{array}$ & $\begin{array}{c}\text { No. of } \\
\text { control }\end{array}$ & Cancer type & $\mathbf{T P}$ & $\mathbf{F P}$ & $\mathbf{F N}$ & $\mathbf{T N}$ \\
\hline $\begin{array}{l}\text { Akahira et al. } \\
\qquad(2007)\end{array}$ & IHC & 164 & 6 & Ovarian cancer & 110 & 0 & 54 & 6 \\
\hline $\begin{array}{l}\text { Dong et al. } \\
\text { (2012) }\end{array}$ & $\mathrm{IHC}$ & 12 & 12 & $\begin{array}{l}\text { Esophageal } \\
\text { squamous cell } \\
\text { carcinoma }\end{array}$ & 12 & 4 & 0 & 8 \\
\hline $\begin{array}{l}\text { Geli et al. } \\
(2005)\end{array}$ & qRT-PCR & 11 & 6 & $\begin{array}{l}\text { Pheochromocytoma } \\
(\mathrm{n}=4) \\
\text { Abdominal } \\
\text { paraganglioma }(\mathrm{n}=7)\end{array}$ & 9 & 0 & 2 & 6 \\
\hline $\begin{array}{c}\text { Jiang et al. } \\
\text { (1999) }\end{array}$ & qRT-PCR & 4 & 3 & Hepatoma & 4 & 1 & 0 & 2 \\
\hline $\begin{array}{c}\text { Tan et al. } \\
(2018)\end{array}$ & IHC & 75 & 150 & $\begin{array}{l}\operatorname{LSCC}(n=52) \\
\operatorname{LAC}(n=23)\end{array}$ & 22 & 10 & 53 & 140 \\
\hline
\end{tabular}

Table 2: Study characteristics of studies included in meta-analysis.

$\mathrm{FN}=$ False negative. $\mathrm{FP}=$ False positive. $\mathrm{IHC}=$ Immunohistochemistry. $\mathrm{LAC}=$ Lung adenocarcinoma. LSCC $=$ Lung squamous cell carcinoma. qRT-PCR $=$ Quantitative reverse transcription-polymerase chain reaction. $\mathrm{TN}=$ True negative. $\mathrm{TP}=$ True positive. 


\section{Table 3 (on next page)}

Quality Assessment of Diagnostic Accuracy Studies - 2 (QUADAS-2) risk of bias assessment. 
Table 3: Quality Assessment of Diagnostic Accuracy Studies - 2 (QUADAS-2) risk of bias assessment.

Quality Assessment of Diagnostic Accuracy Studies - 2 (QUADAS-2)

\begin{tabular}{cccccccc}
\hline Study & \multicolumn{3}{c}{ Risk of bias } & & \multicolumn{2}{c}{ Applicability concerns } \\
\cline { 2 - 7 } & $\begin{array}{c}\text { Patient } \\
\text { selection }\end{array}$ & $\begin{array}{c}\text { Index } \\
\text { test }\end{array}$ & $\begin{array}{c}\text { Reference } \\
\text { standard }\end{array}$ & $\begin{array}{c}\text { Flow } \\
\text { and } \\
\text { timing }\end{array}$ & $\begin{array}{c}\text { Patient } \\
\text { selection }\end{array}$ & $\begin{array}{c}\text { Index } \\
\text { test }\end{array}$ & $\begin{array}{c}\text { Reference } \\
\text { standard }\end{array}$ \\
\hline $\begin{array}{c}\text { Akahira et al. } \\
(2007)\end{array}$ & Low & Low & Low & Low & Low & Low & Low \\
$\begin{array}{c}\text { Dong et al. } \\
(2012)\end{array}$ & Low & Low & Low & Low & Low & Low & Low \\
$\begin{array}{c}\text { Ge et al. } \\
(2015)\end{array}$ & Low & Unclear & Low & Low & Low & Low & Low \\
$\begin{array}{c}\text { Geli et al. } \\
(2005)\end{array}$ & Low & Unclear & Low & Low & Low & Low & Low \\
$\begin{array}{c}\text { Jiang et al. } \\
(1999)\end{array}$ & Unclear & Unclear & Low & Low & Low & Low & Low \\
$\begin{array}{c}\text { Tan et al. } \\
(2018)\end{array}$ & Low & Unclear & Low & Low & Low & Low & Low \\
\hline
\end{tabular}




\section{Table 4 (on next page)}

Grading of Recommendations, Assessment, Development, and Evaluations (GRADE) evidence profile for the studies included in the meta-analysis.

$\mathrm{ND}=$ Not determined. QUADAS-2 = Quality Assessment of Diagnostic Accuracy Studies -2.

TSA $=$ Trial sequential analysis. 
Table 4: Grading of Recommendations, Assessment, Development, and Evaluations (GRADE) evidence profile for the studies included in the meta-analysis.

Grading of Recommendations, Assessment, Development, and Evaluations (GRADE)

\begin{tabular}{|c|c|c|c|c|c|c|c|c|}
\hline Outcome & No. of studies & Design & Risk of bias & Indirectness & Inconsistency & Imprecision & $\begin{array}{c}\text { Publication } \\
\text { bias }\end{array}$ & $\begin{array}{c}\text { Quality of } \\
\text { evidence }\end{array}$ \\
\hline $\begin{array}{l}\text { True positives } \\
\text { (patients/samples with solid } \\
\text { tumor) }\end{array}$ & $\begin{array}{c}5 \text { studies (443 } \\
\text { patients/samples) }\end{array}$ & $\begin{array}{l}\text { Cross- } \\
\text { sectional } \\
\text { studies }\end{array}$ & Not serious & Serious $^{1}$ & Not serious & Serious $^{2}$ & $\mathrm{ND}^{3}$ & Very low \\
\hline $\begin{array}{l}\text { False negatives } \\
\text { (patients/samples incorrectly } \\
\text { classified as not having solid } \\
\text { tumor) }\end{array}$ & $\begin{array}{c}5 \text { studies (443 } \\
\text { patients/samples) }\end{array}$ & $\begin{array}{l}\text { Cross- } \\
\text { sectional } \\
\text { studies }\end{array}$ & Not serious & Serious $^{1}$ & Not serious & Serious $^{2}$ & $\mathrm{ND}^{3}$ & \\
\hline $\begin{array}{l}\text { True negatives } \\
\text { (patients/samples without } \\
\text { solid tumor) }\end{array}$ & $\begin{array}{c}5 \text { studies (443 } \\
\text { patients/samples) }\end{array}$ & $\begin{array}{l}\text { Cross- } \\
\text { sectional } \\
\text { studies }\end{array}$ & Not serious & Serious $^{1}$ & Not serious & Serious $^{2}$ & $\mathrm{ND}^{3}$ & Ver \\
\hline $\begin{array}{l}\text { False positives } \\
\text { (patients/samples incorrectly } \\
\text { classified as having solid } \\
\text { tumor) }\end{array}$ & $\begin{array}{c}5 \text { studies (443 } \\
\text { patients/samples) }\end{array}$ & $\begin{array}{l}\text { Cross- } \\
\text { sectional } \\
\text { studies }\end{array}$ & Not serious & Serious $^{1}$ & Not serious & Serious $^{2}$ & $\mathrm{ND}^{3}$ & Very low \\
\hline $\begin{array}{l}{ }^{1} \text { All samples undergo both in } \\
{ }^{2} \text { Most of the individual studie } \\
{ }^{3} \text { Publication bias could not be }\end{array}$ & $\begin{array}{l}x \text { test and referenc } \\
\text { lave a wide confic } \\
\text { valuated as the nu }\end{array}$ & $\begin{array}{l}\text { tandard, } \\
\text { ce interv } \\
\text { er of stu }\end{array}$ & $\begin{array}{l}\text { ducing indi } \\
\text { inconclus } \\
\text { is }<10 \text {. }\end{array}$ & $\begin{array}{l}\text { ness into the s } \\
\text { TSA results. }\end{array}$ & & & & \\
\hline
\end{tabular}

